\title{
Tocilizumab improves survival in severe COVID-19 pneumonia with persistent hypoxia: A retrospective cohort study with follow-up from Mumbai, India
}

YOJANA Gokhale ( $\square$ yojana1962@gmail.com )

Lokmanya Tilak Municipal Medical College, Sion Mumbai-400022, India https://orcid.org/0000-00031119-419X

\section{Rakshita Mehta}

Lokmanya Tilak Municipal Medical College, Sion Mumbai-400022, India

\section{Uday Kulkarni}

Christian Medical College, Vellore, Tamil Nadu, India

Nitin Karnik

Lokmanya Tilak Municipal Medical College, Sion Mumbai-400022, India

Sushant Gokhale B.Tech

Lokmanya Tilak Municipal Medical College, Sion Mumbai-400022, India

Uma Sundar

Lokmanya Tilak Municipal Medical College, Sion Mumbai-400022, India

\section{Swati Chavan}

Lokmanya Tilak Municipal Medical College, Sion Mumbai-400022, India

\section{Akshay Kor}

Lokmanya Tilak Municipal Medical College, Sion Mumbai-400022, India Sonal Thakur

Lokmanya Tilak Municipal Medical College, Sion Mumbai-400022, India Trupti Trivedi

Lokmanya Tilak Municipal Medical College, Sion Mumbai-400022, India Naveen Kumar

Lokmanya Tilak Municipal Medical College, Sion Mumbai-400022, India

\section{Sujata Bavej}

Lokmanya Tilak Municipal Medical College, Sion Mumbai-400022, India

\section{Aniket Wadal}

Lokmanya Tilak Municipal Medical College, Sion Mumbai-400022, India

\section{Shaonak Kolte}

Lokmanya Tilak Municipal Medical College, Sion Mumbai-400022, India

\section{Aukshan Deolankar}

Lokmanya Tilak Municipal Medical College, Sion Mumbai-400022, India 


\section{Sangeeta Pednekar}

Lokmanya Tilak Municipal Medical College, Sion Mumbai-400022, India

\section{Lalana Kalekar}

Lokmanya Tilak Municipal Medical College, Sion Mumbai-400022, India

\section{Rupal Padiyar}

Lokmanya Tilak Municipal Medical College, Sion Mumbai-400022, India

\section{Charulata Londhe}

Lokmanya Tilak Municipal Medical College, Sion Mumbai-400022, India

\section{Pramod Darole}

Lokmanya Tilak Municipal Medical College, Sion Mumbai-400022, India

\section{Sujata Pol}

Lokmanya Tilak Municipal Medical College, Sion Mumbai-400022, India

\section{Seema Bansode Goke}

Lokmanya Tilak Municipal Medical College, Sion Mumbai-400022, India

\section{Namita Padwal}

Lokmanya Tilak Municipal Medical College, Sion Mumbai-400022, India

\section{Dharmendra Pandye}

Lokmanya Tilak Municipal Medical College, Sion Mumbai-400022, India

\section{Dhirendra Yadav}

Lokmanya Tilak Municipal Medical College, Sion Mumbai-400022, India

\section{Anagha Joshi}

Lokmanya Tilak Municipal Medical College, Sion Mumbai-400022, India Harshad Badgujar

Lokmanya Tilak Municipal Medical College, Sion Mumbai-400022, India

\section{Mayuri Trivedi}

Lokmanya Tilak Municipal Medical College, Sion Mumbai-400022, India

\section{Priyanshu Shah}

Lokmanya Tilak Municipal Medical College

\section{Prerana Bhavsar}

Lokmanya Tilak Municipal Medical College

\section{Research Article}

Keywords: IL-6, Interlukin-6, Cytokine storm, Hyperinflammatory syndrome, CO-RADS, CT-severity score

Posted Date: October 7th, 2020

DOI: https://doi.org/10.21203/rs.3.rs-88185/v1 
License: (c) (i) This work is licensed under a Creative Commons Attribution 4.0 International License. Read Full License

Version of Record: A version of this preprint was published at BMC Infectious Diseases on March 5th, 2021. See the published version at https://doi.org/10.1186/s12879-021-05912-3. 


\section{Abstract}

Background: Cytokine storm triggered by Severe Corona Virus Disease 2019 (COVID-19) is associated with high mortality. With high 'Interlukin -6' (IL-6) levels reported in COVID-19 deaths in China ${ }^{1}$, IL-6 is considered to be the key player in COVID-19 cytokine storm. Tocilizumab, a monoclonal antibody against IL-6 receptor, is used on compassionate grounds for treatment of COVID-19 cytokine storm. Aim of this study was to assess effect of tocilizumab on mortality due to COVID-19 cytokine storm.

Method: This retrospective, observational study included patients of severe COVID-19 pneumonia with persistent hypoxia (defined as saturation $94 \%$ or less on supplemental Oxygen of $15 \mathrm{~L}$ per minute through non-rebreathing mask or PaO2/FiO2 ratio of less than 200) who were admitted to tertiary care center in Mumbai, India, between $31^{\text {st }}$ March to $5^{\text {th }}$ July 2020. In addition to standard care, single Inj. Tocilizumab $400 \mathrm{mg}$ was given intravenously to 151 consecutive COVID-19 patients with persistent hypoxia from $13^{\text {th }}$ May to $5^{\text {th }}$ July 2020 . These 151 patients were retrospectively analysed and compared with historic controls i.e consecutive COVID-19 patients with persistent hypoxia, defined as above ( $N=118$, from our first COVID-19 admission on $31^{\text {st }}$ March to $12^{\text {th }}$ May 2020 ie till tocilizumab was available in hospital). Univariate and multivariate Cox regression analysis was performed for identifying predictors of survival. Statistical analysis was performed using IBM SPSS version 26.

Results: On multivariate Cox regression analysis, independent predictors of survival were use of tocilizumab (HR 0.621, 95\% $\mathrm{Cl} 0.427-0.903, \mathrm{P} 0.013)$ and higher oxygen saturation.

Conclusion: Tocilizumab improved survival in severe COVID-19 pneumonia with persistent hypoxia

\section{Background}

In December 2019, a newly discovered corona virus, SARS-CoV-2 caused the novel corona virus disease (COVID-19), that spread rapidly to become a pandemic. Though around $80 \%$ patients have a mild course and overall mortality is $2-3 \%$ only, around $20 \%$ need hospitalization ( $14 \%$ have severe disease and $5 \%$ are critical) ${ }^{2}$. Mortality is high in those with severe acute lung injury. With absence of specific antiviral drugs, treatment is essentially empirical, supportive and symptomatic, with

- antiviral - Lopinavir/ Ritonavir ${ }^{3}$, Remdesivir ${ }^{4}$, Favipiravir, Oseltamavir, Interferons, Ivermectin ${ }^{5}$ (in vitro reduction in viral load)

- Convalescent plasma with passive antiviral antibodies transfer,

- drugs to reduce virus induced inflammatory response including Methyl Prednisolone and IL-6 blockade with Tocilizumab,6,7,8,9, JAK-inibitors ${ }^{10}$

- conventional or Low Molecular Weight Heparin (LMWH) for virus induced coagulopathy ${ }^{11,12}$

- Hydroxychloroquin and Azithromycin 
- supportive - Oxygen therapy/ high flow nasal cannula, non-invasive ventilation, mechanical ventilator, extracorporeal membrane oxygenation, antibiotics ( to treat secondary infection ), inotropic support and renal replacement.

Autopsy studies from deaths due to corona virus infection suggested that aberrant host immune response results in a lethal inflammatory cytokine storm. ${ }^{13}$ Increased alveolar exudates caused by aberrant host immune response and inflammatory cytokine storm probably impedes alveolar gas exchange and contributes to the mortality of severe COVID-19 patients. IL- 6 is one of the most important cytokines involved in COVID-19 cytokine storm. Therefore tocilizumab, a humanized monoclonal antibody against IL-6 receptor (IL-6R) is investigated in treatment of seriously ill COVID-19 patients with cytokine storm. Untreated cytokine storm can progress from respiratory failure, to cardiovascular collapse, multiorgan dysfunction, and death.

\section{Methods}

Study design and participants: This is a retrospective, observational study done at a single tertiary care center in Mumbai, India. The study population included adults of age more than 18 years with a positive nasopharyngeal swab for COVID-19 by RT-PCR, admitted from $31^{\text {st }}$ March-5 $5^{\text {th }}$ July 2020.

Inclusion criteria were:

- persistent hypoxia (defined as saturation $94 \%$ or less on supplemental Oxygen of $15 \mathrm{~L}$ per minute through non-rebreathing mask or PaO2/FiO2 ratio of less than 200),

- bilateral pulmonary infiltrates on chest $x$-ray and

- raised inflammatory markers ( C-Reactive Protein, Lactose Dehydrogenase, Ferritin)

Tocilizumab was available to us (free through the Municipal Corporation of Greater Mumbai) from $13^{\text {th }}$ May onwards and was used in patients satisfying inclusion criteria from $13^{\text {th }}$ May to $5^{\text {th }}$ July. Although all three inclusion criteria were mandatory in tocilizumab group, in the historic control group the only two mandatory inclusion criteria applied were persistent hypoxia as defined above and presence of bilateral alveolar shadows. High C-reactive Protein could not be applied as inclusion criterion in the historic control group due to non availability of this test in our institute at that time, with prevalent financial constraints at that time.

Exclusion Criteria were:

- altered sensorium

- hypotension requiring multiple inotropic agents or multisystem organ failure (MSOF)

- patients suffering from terminal malignancy 
- cardiomyopathy with ejection fraction less than 20

Clinical features, co-morbidities, laboratory investigations and treatment details of all patients satisfying inclusion criteria were recorded. We have follow up of 55 days after last patient enrolment. Historic control group consisted of patients with COVID-19 infection satisfying inclusion criteria, from $31^{\text {st }}$ March to $12^{\text {th }}$ May (i.e, from first COVID-19 admission to our hospital till tocilizumab became available). Their data was obtained from indoor papers medical records. The study was approved by the Institutional Ethical Committee. Written consent for compassionate use of tocilizumab was obtained from patient or relative, and a consent waiver was permitted by institutional ethics committee for this retrospective study.

Procedures:

All patients received standard treatment consisting of antibiotics (Piperacilin-Tzobactum or Meropenem/ Vancomycin in view of critical condition), hydroxychloroquine $400 \mathrm{mg}$ once daily, ivermectin $12 \mathrm{mg}$ once daily, oseltamivir $75 \mathrm{mg}$ twice daily, low molecular weight heparin $1 \mathrm{mg} / \mathrm{kg}$ subcutaneously once daily (twice daily if D-dimer $>3000 \mathrm{ng} / \mathrm{mL}$ ), methylprednisolone $125-500 \mathrm{mg}$ intravenously once daily, and other supportive care as needed ( Oxygen through non-rebreathing mask, High Flow Nasal Canula, Noninvasive or invasive ventilator support, inotropic support, renal replacement therapy). In addition to standard treatment, tocilizumab group received single intravenous dose of $400 \mathrm{mg}$ tocilizumab.

Outcomes: Primary outcome was death or recovery.

Statistical analysis: Comparison of the characteristics of the patients who received tocilizumab versus the control group, and comparison of characteristics of patients who survived versus those who died was performed. For comparison of categorical data, chi square test was used while for ordinal or continuous data, independent samples Mann Whitney $U$ test was used. A p value of less than 0.05 was considered as significant.

Univariate and multivariate Cox regression analysis and logistic regression were performed for identifying predictors of survival. Log rank test was used to compare survival between patients who received tocilizumab versus the control group. Survival time was calculated from the date of giving tocilizumab to avoid immortal time bias. Statistical analysis was performed using IBM SPSS version 26.

\section{Results}

From $31^{\text {st }}$ March to $5^{\text {th }}$ July 2020, a total of 2183 COVID-19 patients were admitted under Medicine department. Three hundred and ninety seven had persistent hypoxia (defined as saturation $94 \%$ or less on supplemental Oxygen of $15 \mathrm{~L}$ per minute through non-rebreathing mask or PaO2/FiO2 ratio of less than 200); of them 128 died within 24 hours of admission and were not included in the study. A total of 269 patients with persistent hypoxia were included in the study. One fifty one received single intravenous infusion of tocilizumab $400 \mathrm{mg}$ and 118 who did not, were historic controls. 
Their characteristics are shown in table 1. Tocilizumab group was younger (53 years v/s 55 years), but had lower mean Oxygen saturation of $86 \%(82-92 \%) \mathrm{v} / \mathrm{s} 91 \%(88-93 \%)$ in the control group. In tocilizumab group $63.6 \%$ had at least one co-morbidity and $36.4 \%$ were without any co-morbidity, where as in the control group $74.6 \%$ had at least one co-morbidity and $25.4 \%$ were without any comorbidity. Tocilizumab group had more patients with obesity and less proportion of patients with hypertension than the control group.

Non invasive ventilation was used in 56/151 patients from tocilizumab group ( 15 of them later required invasive ventilation) but in none from control group (as a rule, it was avoided initially due to fear of aerosolization with increased risk to health care workers). Overall, 30 patients required invasive ventilation (22 from tocilizumab group and 8 from control group). Inotropic support was required in 11 patients from tocilizumab group and 7 patients from control group. In tocilizumab group, 79 out of 151 died (52.3\% mortality) and in control group 74 out of 118 died (62.7\%). Figure 1 depicts effect of tocilizumab on overall survival. (The median survival in the tocilizumab group was significantly longer than in the control group; 18 days ( $95 \% \mathrm{Cl}$ : 11.3 to 24.7 ) versus 9 days ( $95 \% \mathrm{Cl}: 5.7$ to 12.3 ); log rank $\mathrm{p}$ 0.007). From tocilizumab group 72 out of 151 patients $(47.7 \%)$ were discharged, whereas from the control group 44 out of 118 (37.3\%) were discharged. Tocilizumab was well tolerated and no adverse drug reactions were noted.

Table 2 shows comparison of the demographic and laboratory parameters in 'overall' survived versus non-survived groups (including both control and tocilizumab groups). Those who survived were significantly younger ( $52 \mathrm{v} / \mathrm{s} 55$ years, $p=0.029)$ and had significantly higher Oxygen saturation $(91 \% \mathrm{v} / \mathrm{s}$ $88 \%, p=0.002)$, lower respiratory rate (30 v/s 36 breaths per min, $p=0.001)$ and lower serum creatinine $(1 \mathrm{mg} / \mathrm{dl} \mathrm{v} / \mathrm{s} 1.3 \mathrm{mg} / \mathrm{dl}, \mathrm{p}=0.001)$. The higher average serum creatinine in the non-survived group probably reflected some degree of hypotension with prerenal element.

Our patients, on the whole, did not have significant leucopenia (white blood cells less than 4000), lymphopenia or thrombocytopenia.

D-dimer level was higher in the 'not-survived' group, ( mean $1411 / \mathrm{ml}$, range of 1000-5000 / ml) than in those who survived ( mean $1000 / \mathrm{ml}$, range of 1000-1927 / ml), but the difference was not statistically significant ( $P$ 0.079).

Total 38 radiological scans (High Resolution CT chest: 26, CT-Pulmonary Angiography: 9, CT-brain: 3) were done in 28 out of 151 patients receiving Tocilizumab. Of these 28 patients, 21 were not on any form of advanced respiratory support at any time. Seven patients had radiological scans done early in the disease and ultimately required advanced respiratory support (HFNC/ NIV/ ventilator). Only 7 out of 68 patients who were on advanced respiratory support (HFNC/ NIV/ Ventilator) had radiological scans done before getting switched to the same. In the 28 patients with radio-imaging available 11 patients expired and 17 were discharged. The CT severity scores were similar in the two groups (median of 21 versus $24 ; \mathrm{p}$ value of 0.343$)$. The median CORAD score was also 6 in both groups ( $p 1.000)$. 
Table 3 depicts univariate and multivariate Cox regression analysis. Data on CRP, SGOT, SGPT, LDH, IL-6, WBC and differential count, platelet count, ferritin and d-dimer was not available in all patients in the control group. Data on respiratory rate was available only for 142 patients and d-dimer data was available for 78 patients. Hence these parameters were not included in the multivariate analysis. On multivariate analysis, 'older age' was not detected to be a risk factor for death. Survival was not different in those with or without any co-morbidity.

The independent predictors of survival were use of tocilizumab (HR 0.621, 95\% Cl 0.427-0.903, P 0.013), higher oxygen saturation ( $\mathrm{HR} 0.969,95 \% \mathrm{Cl} 0.950-0.989, \mathrm{p} 0.002)$ and use of invasive ventilation (HR $2.31,95 \% \mathrm{Cl}: 1.442-3.701, \mathrm{p} 0.001)$ on multivariate analysis.

Table 4 depicts comparison of the characteristics of the patients who survived ( $N=72$ ) versus those who did not $(\mathrm{N}=79)$, in the tocilizumab group. Tocilizumab was administered on $2^{\text {nd }}$ to 5 th day of admission (average $3^{\text {rd }}$ day) in both groups. Those who 'survived' had higher Oxygen saturation than 'non-survived group' ( mean $88 \%$ with a range of $85-93 \% \mathrm{v} / \mathrm{s}$ mean $85 \%$ and range of $79-90 \%-p=0.014$ ) and were less tachypnic than 'non-survived group'(respiratory rate $30 \mathrm{v} / \mathrm{s} 36$ breaths per min, $\mathrm{p}=0.002$ ), at the time of enrolment for tocilizumab. Obesity and raised serum creatinine, on the other hand, had adverse effect on survival, $p=0.039$ and 0.001 respectively. Blood levels of inflammatory markers were comparable in both groups. D-dimer was higher in those who did not survive than in those who survived, but the difference was not statistically significant. Proportion of patients who required invasive ventilation was significantly more amongst patients who died as compared to those who survived $(26.6 \%$ versus $1.4 \%, p$ $0.001)$.

\section{Discussion}

We found a significant reduction in risk of death in severe COVID-19 pneumonia with persistent hypoxia receiving a single dose of intravenous tocilizumab $400 \mathrm{mg}$, compared with those treated with standard care alone. The hazards of dying in the tocilizumab group was 0.621 times of that in the control group. We reported $47.1 \%$ mortality in our first 70 patients of severe COVID-19 pneumonia with persistent hypoxia treated with tocilizumab till $5^{\text {th }}$ June 2020 , compared with $67 \%$ mortality in 90 controls (three weeks prior to availability of tocilizumab) with persistent hypoxia due to severe COVID pneumonia ${ }^{14}$. At three weeks follow-up 11 / 151(15.7\%) patients were still hospitalized. Two of them died later, increasing mortality to $50 \%$ in tocilizumab group. In a retrospective observational study in COVID 19 patients treated in ICU in New Jersey, Noa et al ${ }^{15}$ reported $49 \%$ mortality in 210 patients treated with tocilizumab and $61 \%$ mortality in 256 patients who did not receive tocilizumab. In present study, 60 out of our 151 patients from tocilizumab group were managed in COVID ICU. Due to non-availability of COVID ICU beds, 15 patients received non-invasive ventilation (NIV) in covid wards, and 7 patients received oxygen through high flow nasal canula (HFNC) in covid wards. Non invasive ventilation was used in 56 patients from tocilizumab group (15 of them later required invasive ventilation) but in none from control group (it was avoided initially due to fear of aerosolization causing increased risk to health care workers). Overall, 30 
patients required invasive ventilation (22 from tocilizumab group and 8 from control group. Many investigators, for example Kewan ${ }^{9}$, Nicola ${ }^{8}$ have used early Tocilizumab in Covid 19 treatment. Nicola et $\mathrm{al}^{7}$ used tocilizumab in patients with peripheral Oxygen saturation $93 \%$ on room air or PaO2/FiO2 less than $300 \mathrm{~mm}$ of $\mathrm{Hg}$, and documented reduction in mortality from $50 \%$ to $7.7 \%$. With early use of tocilizumab, Nicola et al ${ }^{8}$ could reduce risk of death by $94 \%$. Although more than $70 \%$ of our admitted patients were hypoxic (Oxygen saturation less than $95 \%$ on ambient air) during hospital stay, the limited availability of tocilizumab made it mandatory for us to formulate strict inclusion criteria for tocilizumab administration. These criteria were formulated by consensus of department members and approved by institutional ethics committee. (saturation $94 \%$ or less on $15 \mathrm{~L}$ per min supplemental Oxygen through nonrebreathing mask or $\mathrm{PaO} 2 / \mathrm{FiO} 2$ less than 200). Depending upon inclusion criteria for use of tocilizumab in severe Covid19 pneumonia, various outcomes are reported. Guaraldi et $\mathrm{al}^{7}$ reported mortality in tocilizumab versus standard care group to be $7 \%$ and $20 \%$ respectively $(P<.0001)$, with inclusion criteria being respiratory rate more than or equal to 30 per min, Oxygen saturation less than or equal to $93 \%$ on room air or $\mathrm{PaO} 2 / \mathrm{FiO} 2$ ratio being 300 or less, and bilateral lung infiltrates more than $50 \%$ being present within 24 to 48 of admission. Rossotti et al $^{16}$ reported tocilizumab use to be associated with a better overall survival (HR 0.499 [ $95 \% \mathrm{Cl} 0.262-0.952$ ], $p=0.035$ ) as compared to control, their inclusion criteria being respiratory rate more than or equal to 30 per min, Oxygen saturation less than or equal to $93 \%$ on room air or $\mathrm{PaO} 2 / \mathrm{FiO} 2$ ratio being 300 or less.

In the current study, clinical response in terms of reduction in Oxygen requirements and respiratory rate was observed within 24-72 hours of tocilizumab infusion in those who responded. C-reactive Protein improved by day 3 to 4 . Amongst patients who received tocilizumab, D-dimer levels were higher in 'nonsurvived' group than in 'survived' group. Although this difference was not statistically significant, suspicion of terminal pulmonary thromboembolic event was high on clinical grounds in the non-survived group. Zhou et al ${ }^{17}$ reported D-dimer more than 1000 nanogram $/ \mathrm{ml}$ to be a risk factor for mortality. A Chinese group has reported that coagulation abnormalities probably did not improve with tocilizumab ${ }^{18}$. Our clinical impression is that patients in whom clinical improvement in terms of reduced Oxygen requirement did not occur had either extensive lung involvement or high D-dimer or pulmonary thrombi on CT-Pulmonary angiography (imaging could not be performed in all patients due to logistics issues in patients on High Flow Nasal Canula or on non-invasive or mechanical ventilators). In 23/26 patients in whom HRCT chest could be performed, CO-RAD score ${ }^{19}$ was 6 (lowest is 1 and highest is 6 ) and average CT-score ${ }^{20}$ was 21 out of 25 . CT-pulmonary angiography was performed in 9 patients, and documented pulmonary thrombi in 3 patients. CT-brain was performed in 3 patients and documented brain infracts in all. One patient with pulmonary thrombus developed two large infarcts in brain despite full dose heparin and streptokinase for pulmonary thrombus. Radiological imaging was not possible in the more severely affected patients due to them being on advanced respiratory support.

The possibility of secondary infection due to immunosuppressants (steroids and tocilizumab), contributing to morbidity, also has to be considered in both Tocilizumab and control groups, though higher antibiotics like Piperacilin Tazobactum or Meropenem / Vancomycin were used in all critically ill 
patients. Procalcitonin levels could not be done due to cost constraints. Presence or absence of any comorbidity did not affect primary out come in the current study.

\section{Conclusion}

Use of tocilizumab confers a significant survival benefit in COVID19 patients with persistent hypoxia despite optimal supportive care.

One of the limitations of this study was that tocilizumab group was overall younger, but this factor was likely to have been offset by lower average Oxygen saturation level in tocilizumab group.

These preliminary results are encouraging. Randomised controlled trials on use of tocilizumab as rescue therapy in patients of severe COVID-19 pneumonia with hypoxia due to hyperinflammatory state, are warranted.

\section{Abbreviations}

1. COVID 19 : Corona Virus Disease 2019

2. IL-6 : Interleukin 6

3. NIV: Non-invasive ventilation

4. HFNC: High Flow nasal canula

5. JAK: Janus kinase

6. RT-PCR: Real time polymerase chain reaction

7. CRP: C- reactive protein

8. SGOT: Serum glutamic-oxaloacetic transaminase.

9. SGPT: Serum glutamic-pyruvic transaminase

10. LDH: Lactose dehydrogenase

11. WBC: White blood Corpuscle

12. CO-RADS: Coronavirus disease 2019 (COVID-19) Reporting and Data System

13. CTPA: Computerised tomography pulmonary angiography

14. HRCT: High resolution computerised tomography

\section{Declarations}

- $\quad$ Ethics approval and consent to participate: We confirm that our study was submitted to and approved by our institutional ethics committee.

Full name of the Ethics committee- Institutional Ethics Committee Human Research, Lokmanya Tilak Municipal Medical College and General Hospital, Registration NumberECR/266/Lokmanya/Inst/MH/2013RR-16 
.https://drive.google.com/file/d/1F92TQgCusWQkGaehGK6rZdy-SfILUI3I/view?usp=sharing

https://drive.google.com/file/d/1R-efOKqilJx_1rPvlma46VV4Nu21LX6l/view?usp=sharing

- $\quad$ Consent to publish: Not Applicable

- $\quad$ Availability of data and materials: raw data available upon reasonable request from the corresponding author.

- $\quad$ Competing interests: Authors have 'No competing interests' to declare

https://drive.google.com/file/d/1sKS5L0833WDpoCt_z9klvCy7kqmOV4Jh/view?usp=sharing

- $\quad$ Funding: Not Applicable

- $\quad$ Authors' Contributions: Submitted

https://drive.google.com/file/d/1GuHR1hSj10Z8PMyGibpvgaXvjbhCrXYF/view?usp=sharing

- $\quad$ Acknowledgements: Submitted

https://drive.google.com/file/d/1oC_pLppZa70QGbRnS0v1t9I11J7_ToEW/view?usp=sharing

\section{References}

1. Fei Zhou, Ting Yu, Ronghui Du, Guohui Fan, Ying Liu, Zhibo Liu,et al, Clinical course and risk factors for mortality of adult inpatients with COVID-19 in Wuhan, China: a retrospectivecohort study, Lancet 2020; 395: 1054-62

2. Zunyou Wu, Jennifer M. McGoogan,, Characteristics of and Important Lessons From the Coronavirus Disease 2019 (COVID-19) Outbreak in China Summary of a Report of 72314 Cases From the Chinese Center for Disease Control and Prevention, JAMA 2020; 323: 1239-42

3. A B Owa, O T Owa, Lopinavir/ritonavir use in Covid-19 infection: is it completely non-beneficial? J Microbiol Immunology and Infection, https://doi.org/10.1016/j.jmii.2020.05.014, accessed on 01.08.2020

4. J. Grein, N. Ohmagari, D. Shin, G. Diaz, E. Asperges, A. Castagna, et al Compassionate Use of Remdesivir for Patients with Severe Covid-19, N Engl J Med 2020;382:2327-36. 
5. Fatemeh Heidary, Reza Gharebaghi, Ivermectin: a systematic review from antiviral effects to COVID19 complementary regimen, The $\mathrm{J}$ of Antibiotics 2020; 73: 593-602

6. Paola Toniatia,1, Simone Pivab,c,1, Marco Cattalinid,e,1, Emirena Garrafaf,g,1, Francesca Regolaa,e, Francesco Castelli, Tocilizumab for the treatment of severe COVID-19 pneumonia with hyperinflammatory syndrome and acute respiratory failure: A single center study of 100 patients in Brescia, Italy, Autoimmunity Reviews, May 2020; https://doi.org/10.1016/j.autrev.2020.102568, accessed on 01.08.2020

7. Giovanni Guaraldi, Marianna Meschiari*, Alessandro Cozzi-Lepri, Jovana Milic, Roberto Tonelli et al, Tocilizumab in patients with severe COVID-19: a retrospective cohort study, Lancet Rheumatology, Published Online June 24, 2020, https://doi.org/10.1016/ S2665-9913(20)30173-9, accessed on 01.08.2020

8. NicolaDeRossia,CristinaScarpazzab,Chiara Filippinia, Cinzia Cordiolia , Sarah Rasiaa, Chiara Rosa Mancinelli, Early use of low dose tocilizumab in patients with COVID19 : A retrospective cohort study with a complete follow-up, E Clinical Medicine 000 (2020) 100459 July 23, 2020;6:47, https://doi.org/10.1016/j.eclinm.2020.100459, accessed on 01.08.2020

9. Tariq Kewana, FahrettinCovuta, Mohammed J.A, Jaghbeerb, Lori Rosec, K.V.Gopalakrishna et al, Tocilizumab for treatment of patients with severe COVID-19:A retrospective cohort study, E Clinical Medicine 24 (2020) 100418, https://doi.org/10.1016/j.eclinm.2020.100418, accessed on 01.08.2020

10. F. La Rosée, H. C. Bremer, I. Gehrke, A. Kehr, A. Hochhau, S. Birndt, M. Fellhauer, M. Henkes, The Janus kinase 1/2 inhibitor ruxolitinib in COVID-19 with severe systemic hyperinflammation, Leukemia, 2020; 34:1805-1815

11. Mouhamed Yazan Abou-Ismaila,b,1 , Akiva Diamonda,b,1 , Sargam Kapoorc, 1, Yasmin Arafaha,b , Lalitha Nayak, The hypercoagulable state in COVID-19: Incidence, pathophysiology, and management, Thrombosis Research, 2020; 194: 101-115

12. Yan Zhang, Meng Xiao, Shulan Zhang, Peng Xia, Wei Cao, Wei Jiang et al Coagulopathy and Antiphospholipid Antibodies in Patients with Covid-19, N Engl J Med, 2020; 382: e-38-39, published on April 23, 2020, visited on 28 August 2020

13. Channappanavar R, Perlman S. Pathogenic human coronavirus infections: causes and consequences of cytokine storm and immunopathology. Semin Immunopathol. 2017;39:529-39

14. Yojana Gokhale, Rakshita Mehta, Nitin Karnik, Uday Kulkarni, Sushant Gokhale. Tocilizumab improves survival in patients with persistent hypoxia in severe COVID-19 pneumonia, E Clinical Medicine 24 (2020) 100467, https://doi.org/10.1016/j.eclinm.2020.100467, visited on 28 August 2020

15. Noa Biran, Andrew Ip, Jaeil Ahn, Ronaldo C Go, Shuqi Wang, Shivam Mathura,. Tocilizumab among patients with COVID-19 in the intensive care unit: a multicentre observational study, Lancet Rheumatol 2020, Published Online August 14, 2020 https://doi.org/10.1016/ S26659913(20)30277-0, visited on $21^{\text {st }}$ August 2020 
16. R. Rossotti, G. Travi and N. Ughi et al., Safety and efficacy of anti-il6-receptor tocilizumab use in severe and critical patients affected by coronavirus disease 2019: A comparative analysis, Journal of Infection, https://doi.org/10.1016/j.jinf.2020.07. 008, visited on 18/9/2020

17. Fei Zhou, Ting Yu, Ronghui Du, Guohui Fan, Ying Liu, Zhibo Liu et al Clinical course and risk factors for mortality of adult in patients with COVID-19 in Wuhan, China: a retrospective cohort study, Lancet 2020; 395: 1054-62

18. Chen J, Wang X, Zhang S, Liu B, Wu X, Wang Y, et al. Findings of acute pulmonary embolism in COVID-19 patients. The Lancet Infectious Diseases, published on 3/1/2020 https://doi.org/10.2139/ssrn.3548771, visited on 28/8/2020

19. Mathias Prokop, Wouter van Everdingen, Tjalco van Rees Vellinga, Henriëtte Quarles van Ufford, Lauran Stöger, Ludo Beenen, et al. CO-RADS: A Categorical CT Assessment Scheme for Patients Suspected of Having COVID-19-Definition and Evaluation, Radiology 2020; 296: E-97-103, published online 27 April, https://doi.org/10.1148/radiol.2020201473, visited on $13^{\text {th }}$ July 2020

20. Chang YC, Yu CJ, Chang SC, Shan-Chwen Chang, Jeffrey R Galvin, Hon-Man Liu, Cheng-Hsiang Hsiao et al. Pulmonary sequelae in convalescent patients after severe acute respiratory syndrome: evaluation with thin-section CT. Radiology 2005;236(3):1067-1075.

\section{Tables}

Table 1: Comparison of the characteristics of the patients who received tocilizumab versus those who did not.

\begin{tabular}{|l|l|l|l|}
\hline Variable & Tocilizumab $(\mathrm{n}=151)$ & Control $(\mathrm{n}=118)$ & P value \\
\hline Age & $53(44-60)$ & $55(47-64)$ & 0.007 \\
\hline Male sex & $107(70.9)$ & $69(58.5)$ & 0.034 \\
\hline Hypertension & $40(26.5)$ & $53(44.9)$ & 0.002 \\
\hline Diabetes & $78(51.7)$ & $59(50)$ & 0.788 \\
\hline Obesity & $14(9.3)$ & $0(0)$ & 0.001 \\
\hline Other comorbidities & $5(3.3)$ & $13(11)$ & 0.012 \\
\hline Number of comorbidities & $1(0-1)$ & $1(1-2)$ & 0.031 \\
& & & \\
\hline No comorbidities & $55(36.4)$ & $28(23.7)$ & 0.035 \\
\hline $\begin{array}{l}\text { Category* } \\
\text { F }\end{array}$ & $125(82.8)$ & $108(91.5)$ & 0.036 \\
\hline Oxygen saturation & $26(17.2)$ & $10(8.5)$ & \\
\hline Respiratory rate & $86(82-92)$ & $91(88-93)$ & 0.001 \\
\hline Serum creatinine & $34(30-40)$ & $30((27-38)$ & 0.137 \\
\hline Non-invasive ventilation & $1(1-1.9)$ & $1.3(1-1.7)$ & 0.002 \\
\hline Invasive ventilation & $22(37.1)$ & $0(0)$ & 0.001 \\
\hline Deaths & $79(52.6)$ & $8(6.8)$ & 0.044 \\
\hline
\end{tabular}

*Revised guidelines on clinical management of COVID-19.Ministry of health \& family welfare,directorate general of health services, government of India, (2020). 
https://www.mohfw.gov.in/pdf/Revised National Clinical Management Guideline forCOVID1931032020.pdf

Table 2: Comparison of the characteristics of the patients who survived versus those who did not (both tocilizumab and control groups )

\begin{tabular}{|c|c|c|c|}
\hline Variable & Survived $(\mathrm{n}=116)$ & Died $(n=153)$ & $\mathrm{P}$ value \\
\hline Age & $52(44-60)$ & $55(47-62)$ & 0.029 \\
\hline Male sex & $71(61.2)$ & $105(68.6)$ & 0.205 \\
\hline Hypertension & $37(31.9)$ & $56(36.6)$ & 0.422 \\
\hline Diabetes & $55(47.4)$ & $82(53.6)$ & 0.315 \\
\hline Obesity & $3(2.6)$ & $11(7.2)$ & 0.092 \\
\hline Other comorbidities & $8(6.9)$ & $10(6.5)$ & 0.907 \\
\hline Number of comorbidities & $1(0-1)$ & $1(0-2)$ & 0.074 \\
\hline $\begin{array}{l}\text { Category } \\
\mathrm{E} \\
\mathrm{F}\end{array}$ & $\begin{array}{l}105(90.5) \\
11(9.5)\end{array}$ & $\begin{array}{l}128(83.7) \\
25(16.3)\end{array}$ & 0.10 \\
\hline Oxygen saturation & $91(86-93)$ & $88(83-92)$ & 0.002 \\
\hline $\mathrm{CRP}$ & $97.5(63.5-159)$ & $90(56-136)$ & 0.264 \\
\hline Respiratory rate & $30(30-36)$ & $36(30-40)$ & 0.001 \\
\hline Serum Creatinine & $1(1-1.2)$ & $1.3(1-2)$ & 0.001 \\
\hline SGOT & $49(37-75)$ & $57(42-72)$ & 0.169 \\
\hline SGPT & $40(30-58)$ & $44(28-68)$ & 0.977 \\
\hline $\mathrm{LDH}$ & $666(275-990)$ & $978(369-2000)$ & 1.000 \\
\hline Ferritin & $437(293-947)$ & $690(369-1257)$ & 0.364 \\
\hline D-dimer & $1000(1000-1927)$ & $1411(1000-5000)$ & 0.079 \\
\hline IL-6 & 455 (75-984) & Not available & \\
\hline WBC counts $\left(\mathrm{x} 10^{9} / \mathrm{L}\right)$ & $8.9(5.85-13.6)$ & $8.55(6.1-12.15)$ & 0.799 \\
\hline Platelet count $\left(\times 10^{9} / \mathrm{L}\right)$ & $200(200-300)$ & $200(200-300)$ & 0.314 \\
\hline CT CORAD & $6(6-6)$ & $6(6-6)$ & 1.000 \\
\hline CT severity score & $21(17-24)$ & $24(21-25)$ & 0.343 \\
\hline Thrombosis on CT & 2 of 8 & 1 of 2 & 0.490 \\
\hline Tocilizumab & $72((62.1)$ & $79(51.6)$ & 0.088 \\
\hline Day of tocilizumab & $3(2-6)$ & $3(2-5)$ & 0.865 \\
\hline Non-invasive ventilation & $22(19)$ & $34(22.2)$ & 0.515 \\
\hline Invasive ventilation & $1(0.9)$ & $29(19)$ & 0.001 \\
\hline
\end{tabular}

Table 3: Univariate and multivariate cox regression analysis 


\begin{tabular}{|l|l|l|l|l|l|l|}
\hline \multirow{2}{*}{ Variable } & \multicolumn{4}{l}{ Univariate } & \multicolumn{3}{l|}{ Multivariate } \\
\cline { 2 - 8 } & HR & 95\%CI & P value & HR & $95 \%$ CI & P value \\
\hline Age & 1.017 & $1.002-1.032$ & 0.029 & 1.012 & $0.994-1.029$ & 0.200 \\
\hline Male Sex & 0.813 & $0.577-1.145$ & 0.237 & & & \\
\hline Hypertension & 0.887 & $0.638-1.233$ & 0.476 & & & \\
\hline Diabetes & 0.983 & $0.714-1.353$ & 0.916 & & & \\
\hline Obesity & 0.805 & $0.435-1.489$ & 0.489 & & & \\
\hline Other comorbidities & 0.926 & $0.487-1.761$ & 0.815 & & & \\
\hline Number of comorbidities & 1.090 & $0.903-1.315$ & 0.371 & & & \\
\hline Oxygen saturation & 0.979 & $0.962-0.996$ & 0.017 & 0.969 & $0.950-0.989$ & 0.002 \\
\hline CRP & 0.999 & $0.996-1.002$ & 0.379 & & & \\
\hline Creatinine & 1.157 & $1.031-1.298$ & 0.013 & 1.123 & $0.995-1.267$ & 0.061 \\
\hline Respiratory rate & 1.045 & $1.006-1.084$ & 0.023 & & & \\
\hline LDH & 1.000 & $0.997-1.003$ & 0.880 & & & \\
\hline Ferritin & 1.000 & $1.000-1.001$ & 0.626 & & & \\
\hline D-dimer & 1.000 & $1.000-1.000$ & 0.043 & & & \\
\hline WBC counts & 1.000 & $1.000-1.000$ & 0.875 & & & \\
\hline Tocilizumab & 0.655 & $0.476-0.901$ & 0.009 & 0.621 & $0.427-0.903$ & 0.013 \\
\hline CT severity score & 1.084 & $0.810-1.449$ & 0.588 & & & \\
\hline Thrombosis & 2.160 & $0.135-34.608$ & 0.586 & & & \\
\hline Non-invasive ventilation & 0.770 & $0.525-1.131$ & 0.183 & & & \\
\hline Invasive ventilation & 2.028 & $1.349-3.049$ & 0.001 & 2.31 & $1.442-3.701$ & 0.001 \\
\hline
\end{tabular}

Data on respiratory rate was available only for 142 patients while d-dimer was available for 78 patients. Hence these parameters were not included in the multivariate analysis

Table 4: Comparison of the characteristics of the patients receiving tocilizumab who survived versus those who did not 


\begin{tabular}{|c|c|c|c|}
\hline Variable & Survived $(\mathrm{n}=72)$ & Died $(n=79)$ & $\mathrm{P}$ value \\
\hline Age & $52(42-59)$ & $55(46-60)$ & 0.105 \\
\hline Male sex & $48(66.7)$ & $59(74.7)$ & 0.279 \\
\hline Hypertension & $19(26.4)$ & $21(26.6)$ & 0.979 \\
\hline Diabetes & $33(45.8)$ & $45(57)$ & 0.172 \\
\hline Obesity & $3(4.2)$ & $11(13.9)$ & 0.039 \\
\hline Other comorbidities & $2(2.8)$ & $3(3.8)$ & 0.727 \\
\hline Number of comorbidities & $1(0-1)$ & $1(0-2)$ & 0.082 \\
\hline $\begin{array}{l}\text { Category } \\
\mathrm{E} \\
\mathrm{F}\end{array}$ & $\begin{array}{l}63(87.5) \\
9(12.5)\end{array}$ & $\begin{array}{l}62(78.5) \\
17(21.5)\end{array}$ & 0.143 \\
\hline Oxygen saturation & $88(85-93)$ & $85(79-90)$ & 0.014 \\
\hline CRP & $97.5(63.5-159)$ & $90(56-136)$ & 0.264 \\
\hline Respiratory rate & $30(30-36)$ & $36(30-40)$ & 0.002 \\
\hline Serum Creatinine & $1(1-1)$ & $1(1-2)$ & 0.001 \\
\hline SGOT & $49(37-75)$ & $57(42-72)$ & 0.169 \\
\hline SGPT & $40(30-58)$ & $44(28-68)$ & 0.977 \\
\hline LDH & $701(515-988)$ & $608(462-753)$ & 1.000 \\
\hline Ferritin & $437(293-947)$ & $978(369-2000)$ & 0.364 \\
\hline D-dimer & $1000(1000-1927)$ & $1411(1000-5000)$ & 0.079 \\
\hline IL-6 & $455(75-984)$ & Not available & \\
\hline WBC counts $\left(\times 10^{9} / \mathrm{L}\right)$ & $8.9(5.85-13.6)$ & $8.4(6.1-12.0)$ & 0.799 \\
\hline Neutrophil percentage & $72(65-78)$ & $72(70-75)$ & 1.000 \\
\hline Lymphocyte percentage & $25(17-29)$ & $23(10-27)$ & 0.469 \\
\hline Platelet count $\left(\mathrm{x} 10^{9} / \mathrm{L}\right)$ & $200(200-300)$ & $200(200-300)$ & 0.314 \\
\hline Day of tocilizumab & $3(2-6)$ & $3(2-5)$ & 0.865 \\
\hline Non-invasive ventilation & $22(30.6)$ & $34(43)$ & 0.113 \\
\hline Invasive ventilation & $1(1.4)$ & $21(26.6)$ & 0.001 \\
\hline
\end{tabular}

\section{Figures}




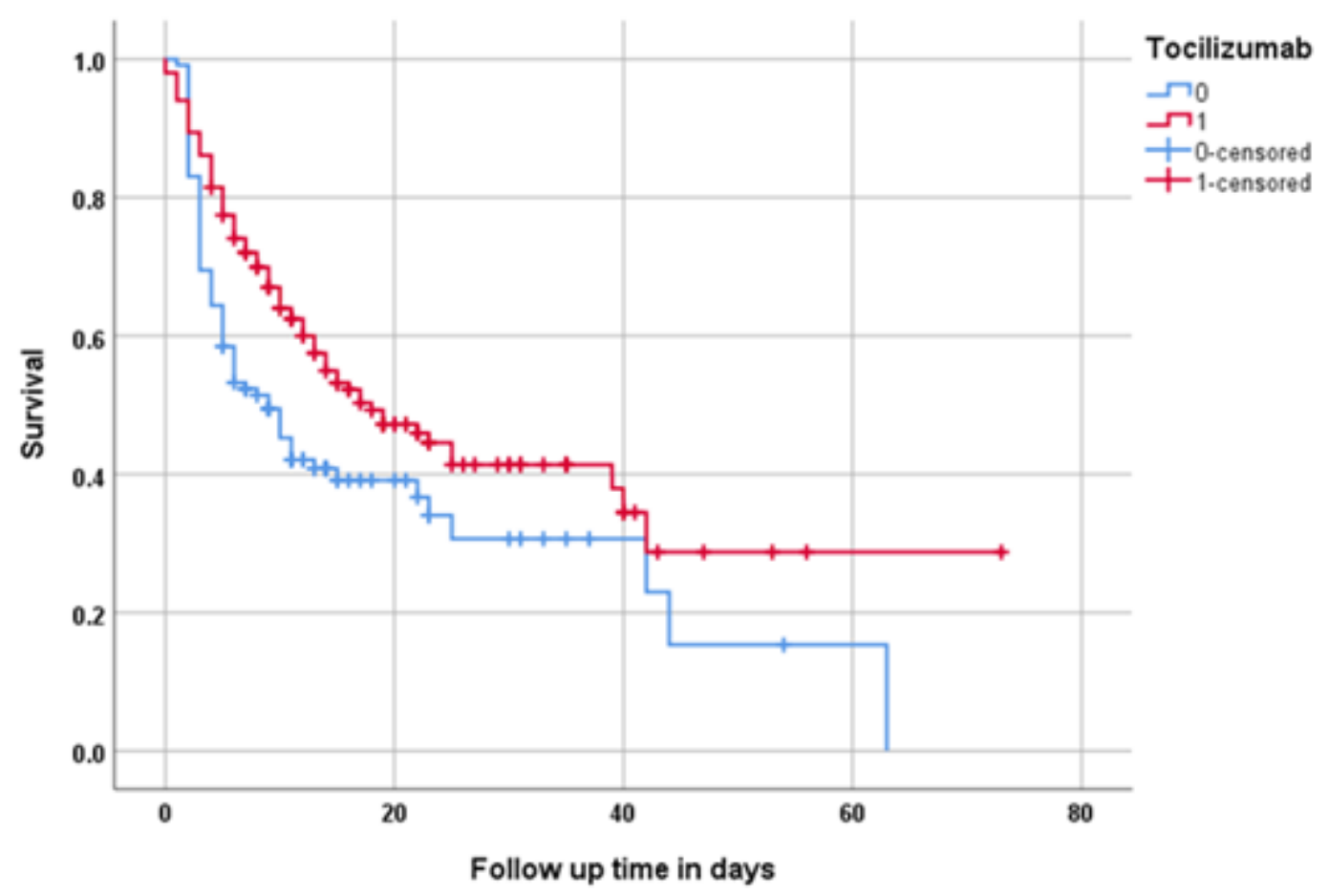

Figure 1

Survival analysis show the effect of tocilizumab on survival. (The median survival in the tocilizumab group was significantly longer than in the control group; 18 days ( $95 \% \mathrm{Cl}: 11.3$ to 24.7 ) versus 9 days (95\% Cl: 5.7 to 12.3$)$; log rank p 0.007) 